\title{
Safety in Cosmetics and Cosmetovigilance, Current Regulations in Türkiye
}

\author{
(D) İmran ALTIOKKA ${ }^{1,2 *}$, (D) Melike ÜNER 2 \\ 1 University of Central Florida, Burnett School of Biomedical Science, Orlando, United States of America \\ 2istanbul University, Faculty of Pharmacy, Department of Pharmaceutical Technology, İstanbul, Türkiye
}

\begin{abstract}
Although it is considered that cosmetics do not have side effects, studies have revealed that a significant number of consumers experience side effects. Undesirable effects arising from the use of cosmetic products have created the need for a reporting and evaluation system, which is responsible for some restrictions on the use of cosmetics ingredients and putting into cosmetic regulation effect, called cosmetovigilance. However, the new cosmetovigilance concept needs some updates to become more effective for public health. For instance, side effects related to cosmetic use have been reported more frequently recently, but this rate is still quite low. Additionally, since the current cosmetic directive does not recognize cosmeceuticals as a distinct category from cosmetics, some products named cosmetic under the laws may affect the bottom layers of dermis and cause systemic side effects. Although the manufacturers must show safety assessments to the Turkish Pharmaceutical and Medical Device Agency to get a license, after launching they do not have post-vigilance reporting to the institution, which is another problem of the system. In this review, the current cosmetovigilance system in Türkiye was discussed and some hardships encountered were criticized regarding the implementation of the system. Additionally, scientific studies are conducted on cosmetic ingredients that can have side effects and contribute to the developing cosmetovigilance concept. Because of the study, the importance of the feedback of healthcare professionals in the cosmetovigilance system, the consultancy service to be given to the consumer and patient about the contents that should be considered. Besides, there is a need for new studies to indicate the adverse reaction incidence related to cosmetics in the Turkish market. Another outcome of this review article is to understand the importance of the new regulations regarding the increase in the new active ingredients in the cosmetic market.
\end{abstract}

Key words: Adverse reactions of the skin, cosmetovigilance, side effects of cosmetics, cosmetic regulations

\section{INTRODUCTION}

The concept of cosmetovigilance was first used by Vigan, a dermatologist in 1997. The meaning of cosmetovigilance is the collection, evaluation, and monitoring of spontaneous reports of undesirable effects observed with the use of cosmetic products under normal or predictable conditions. The first study on a cosmetovigilance system was conducted in France in 2002. ${ }^{2}$ Thereafter, in line with the 76/768 EEC EU cosmetics directive, the first guideline on reporting adverse reactions was published in 2005 by COLIPA, which is called an undesirable event report (COLIPA, 2005). ${ }^{3.4}$ In 2006, after a pilot study conducting by carried out by the Council of Europe's Committee of Experts on Cosmetic Products in 2004-2005, the EU Public Health Committee decided to establish the ResAP as a cosmetovigilance system based on case reports, which forms the basis of the current system. ${ }^{5}$ Afterward, cosmetovigilance systems were established in Belgium, Denmark, Sweden, Italy, Germany, and Norway.

The cosmetovigilance system in our country was founded by Turkish Pharmaceutical and Medical Device Agency (TITCK) parallel to the 1223/2009 EC Regulation in 2012. ${ }^{6}$ By force of the guide on the reporting of undesirable effects, the notification, and reporting of side effects related to cosmetics can be followed.

The necessity of a cosmetovigilance system has been proven by some pilot studies. In a pilot cosmetovigilance study conducted in the Netherlands in 2012, 1294 cases of adverse reactions related to the use of cosmetics were examined. ${ }^{7}$ It was found that $23 \%$ of the patients were allergic to isothiazolinone, $21 \%$ to the perfume mixture, and $21 \%$ to cocamidopropyl betaine. The small number of reported cases has been thought to be because a healthcare professional was not notified, when side 
effects occurred, the patient tried to self-medicate and ignored the side effects, and often cosmetics did not take the risk of side effects seriously enough. Simultaneously, the absence of a formal and reliable cosmetovigilance system makes it difficult to evaluate the reactions that occur as a standard. ${ }^{8}$

In this review, detailed information about the side effects of some cosmetic ingredients will be given, the recent regulations about the cosmetics and the current cosmetovigilance system in Türkiye will be explained.

\section{Cosmetics and cosmeceutical concepts}

Although cosmetics and cosmeceuticals represent different types of products, these two concepts are referred under "cosmetics" in the laws in Türkiye. Cosmetics are preparations that are applied externally to the skin, oral mucosa, hair, nails, sweat glands, and do not change the structure and functions of the skin. However, cosmeceuticals are products with active ingredients that reach deeper layers in the skin and display physiological effects. Therefore, the regulations related to cosmetics and cosmeceuticals should also be separately made.

Although the definition of cosmeceutical or dermocosmetic (cosmeceuticals) is unofficially included in the regulations made by the Food and Drug Administration (FDA) in the USA, the term "over-the-counter (OTC) drug" is included for products that fall between cosmetics and pharmaceuticals. ${ }^{9}$ The FDA reports the requirements for OTC drugs in its OTC drug monographs. ${ }^{10}$ The OTC drug monographs contain allowed ingredients and quantities, doses of active ingredients, formulations, and label rules. It decides that the cosmetic preparation should be evaluated as a cosmetic or OTC preparation with its "intended use".

With a similar approach, European countries have interpreted this class between cosmetics and pharmaceuticals differently. ${ }^{11}$ This group, defined as "borderline products", refers to the situations, where it cannot be decided whether the product is a cosmetic or drug. The EU Commission publishes guidelines for these situations describing the cases and explaining which legislation is subject to which situation. ${ }^{12}$ For example; although skin whitening cosmetics are included in the cosmetic class, if they are intended to treat diseases such as melasma lentigo, these products are subject to the medical product legislation. ${ }^{13}$ Another example is that a bath foam claimed "relaxing" effect will normally be considered a cosmetic product. However, if the product is used for the treatment of cold or flu, it may be considered a medicinal product. These classifications are made by the subgroup on borderline products on the scope of application of Cosmetic Regulation EC no. 1223/2009 and then approved by the working group on the cosmetic products.

Since cosmeceuticals are not a defined group and are not subject to separate regulations from drugs and cosmetics, it is possible to say that products arising from this uncertainty confuse the cosmetovigilance system. Since the steps required for drugs to obtain a license and the procedures for cosmetics are not the same, manufacturers can market products with high active content under the name of cosmetics, as it is easier to obtain a license. However, since these intermediate products, which should be defined as cosmeceuticals, have different effects compared to cosmetics, their control and regulation should be different from cosmetics. It will be revealed in the rest of our article that the products on the market today that create a question mark in the cosmetovigilance system show much a more active cosmeceutical effectiveness than simple superficial effects.

\section{Cosmetovigilance system in Türkiye}

EC Cosmetics Regulation $1223 / 2009$ by the European Commission under Guidelines for Reporting Serious Adverse Effects was published in 2012 and this context has been established in Türkiye by TITCK in the same year. In practice, the cosmetovigilance system is applied by healthcare professionals (pharmacists, dentists, physicians, and nurses), who observed the adverse reactions via their institution, manufacturer, company, or clinic with the Cosmetic Product Undesirable Effect/Serious Undesirable Effect Notification Forms.

TITCK also defines the responsibilities of cosmetic manufacturers and audits them within the cosmetovigilance system to monitor and evaluate all suspected undesirable effects of products reaching the manufacturer. The manufacturer is responsible for collecting, recording, archiving and evaluating information about the risks and reliability of the products. It ensures that up-to-date information is kept in the product information files of cosmetics, moreover, serious undesirable effect notifications are made to TITCK.14 The notifications, pieces of information, and reports are evaluated and received by the TITCK, when necessary, opinions are taken by submitting them to the Scientific Commission. Because of the evaluations made, the changes or additions deemed to be made in the product information file or on the packaging of the product are notified to the manufacturer by TITCK. Although cosmetic product manufacturers have the responsibility to report the analysis results and regulate their contents according to legal limits when notifying cosmetic products, sometimes production conditions that do not comply with regulations may occur. In such cases, the production facility is inspected with side effect notifications related to cosmetics. The product having side effects is analyzed by TITCK and can be recalled from the market if it is not found suitable. Since feedback can prevent the occurrence of such situations, it is crucial for public health.

\section{Difficulties encountered in the implementation of the cosmetovigilance system}

Even though there is a well-established cosmetovigilance system in Türkiye, it may need some new regulations and implementations to make it more effective.

For instance, since the companies only must prove the use the safe ingredients and their use limits according to the law, the final product is usually not evaluated by the laboratories. This gap may have an adverse effect on the end cosmetic products after getting a license. According to a study conducted in Türkiye, which is the only study in this field, it has been recommended that the post-marketing vigilance systems such as using in vitro tests for ingredients and the end products should be done continuously and supported by the authorities. ${ }^{15}$ 
The new formation of the cosmetovigilance concept makes it difficult to follow up the side effect forms. In some studies, it has been reported that this issue is not considered sufficiently important by health professionals regarding the side effects related to cosmetics. . $^{15} 16$ Unfortunately, feedback on undesirable effects related to cosmetic products is quite limited. The reason for this is that the consumer stops using the cosmetic product and treats the disorder without consulting a healthcare professional when a mild or moderate side effect is observed. ${ }^{8}$ Since these side effects are mostly not at a worrisome level, healthcare professionals may not have time to provide feedback even if they encounter any case.

Cosmetovigilance also prevents possible risks against toxic ingredients by reporting undesirable effects caused by cosmetics. Therefore, healthcare professionals must know which ingredients may have these side effects to provide preventive health services to their patients. However, since cosmetic side effects are not generally seen as serious reactions, current cosmetovigilance training is not given to health professionals.

Another important thing to be recognized in the literature needs more study done in the Turkish cosmetic market to show the incidence of observed adverse reactions related to cosmetics in the Turkish population, identify the potential risks of end formulations, or indicate the public awareness in this matter.

Moreover, cosmetovigilance is a concept that lives and is constantly changing. Factors such as socio-economic developments, differing cosmetic trends, marketing strategies of cosmetic products increase people's cosmetic use. The increasing use of cosmetics causes people to be exposed to more chemicals. Changing cosmetic usage habits and contents creates the need to determine new regulations following the current situation.

\section{Adverse reactions related to cosmetic ingredients}

Several scientific studies have been conducted to determine the frequency of occurrence of side effects related to cosmetics. In a study, it was found that $24 \%$ of cosmetic consumers experienced any side effects. ${ }^{17}$ Cutaneous side effects constitute $95.9 \%$ of total side effects, and $4.1 \%$ of systemic side effects. In this study, it was also reported that the most common cutaneous side effects were rash (34.8\%), itching (31.5\%), eczema (22.8\%), and others. Systemic side effects were stated as headache $(1.7 \%)$, nausea (1\%), dizziness $(0.6 \%)$, dyspnea $(0.3 \%)$ and other conditions.

In one of the recent studies conducted in 2019, the occurrence of adverse effects in 341 subjects diagnosed with contact dermatitis induced by cosmetics was recorded using forms. The occurrence of cosmetics-related adverse events was associated with the mixing of different types of cosmetic products (31.4\%), among which mixing of two different brands accounted for $65.4 \% .^{18}$ Among the patients, the most common symptom recorded was contact dermatitis ( $n: 318$ ), followed by rosacea and perioral dermatitis ( $n: 12)$ and acne was 3 out of 341.

A pilot study conducted in a dermatology clinic in 2019 revealed that the incidence of cutaneous adverse reactions related to cosmetics was $1.58 \% .^{19}$ The most common reaction was rash and pruritus accounted for $30.9 \%$, followed by itching $23.8 \%$.

Twelve dermatologists from the United States examined contact dermatitis patients from 1977 to 1983 to identify the effect of cosmetic products in their dermatitis occurrence. Skincare products, hair preparations (including colors), and facial make-up was responsible for most of the reactions. One of the important findings was that half of the the patients or physicians were unaware that a cosmetic was responsible for their dermatitis. ${ }^{20}$

Adverse effects related to cosmetic products can be classified as contact dermatitis, acne, discoloration of the skin and its appendages, conditions caused by endocrine-disrupting components, and systemic side effects.

\section{a. Contact dermatitis}

Allergic contact dermatitis is defined as allergic or inflammatory dermatosis due to a late-type hypersensitivity reaction, which can occur with the effect of allergen substances that encounter the skin. A European standard patch test is performed to understand, which ingredients have developed allergies in patients. ${ }^{21}$

The European standard patch test is implemented with different types of chambers loaded with allergens at required doses. The upper back is the preferred site for patch testing and the recommended occlusion time is 2 days. Afterward, readings are performed on day 2,3,4 or day 7. The patch test is scored according to morphology. ${ }^{22} \mathrm{~A}$ positive patch test reaction is

Table 1. Reading criteria of patch testing ${ }^{22}$

\begin{tabular}{lll} 
Symbol & Morphology & Assessment \\
\hline- & No reaction & The negative reaction \\
\hline$?+$ & Faint erythema only & Doubtful reaction \\
\hline+ & Erythema, infiltration, possibly papules & Weak-positive reaction \\
\hline++ & Erythema, infiltration, papules, vesicles & Strong-positive reaction \\
\hline+++ & Erythema, infiltration, coalescing vesicles & The extreme positive reaction \\
\hline IR & Various morphologies & The irritant reaction \\
\hline
\end{tabular}

IR: Irritant reaction 
defined as a reaction that fulfills the criteria of at least one positive reaction (Table 1 ).

In a survey conducted in an epidemiology hospital in the Netherlands, it was reported that $70 \%$ of the side effects that patients experienced personal care product cosmetic side effects were itching, 63\% dry skin, and 50\% burning. ${ }^{23}$ In a study conducted in China between 2015 and 2017, contact dermatitis was reported as the most common reaction among the side effects associated with cosmetics. ${ }^{18}$ The applications of 151 patients who came to 3 different dermatology clinics in Sweden with the complaints of skin reaction to cosmetics were evaluated and allergic contact dermatitis was diagnosed in $28 \%$ and irritant reaction in $27 \% .^{16}$ Cosmetic preparations that most commonly cause allergic contact dermatitis are hair dyes, moisturizers, deodorants, perfumes, facial cleansers, and nail polishes.

Most common cosmetic allergens, which are the causative agents of allergic contact dermatitis, can be listed as perfume ingredients, hydrogen peroxide, ammonium persulfate, butylated hydroxyanisole, butylated hydroxytoluol, Peru balm, henna, benzophenones, nickel, formaldehyde, paraben, lanolin derivatives, propylene glycol, $p$-phenylenediamine, tosylamide/ formaldehyde resin, glyceryl thioglycolate, cetyl alcohol, cocoamidopropyl stearate, 2-bromo-2-nitro-propane-1,3-diol, imidazolidinyl urea, phenoxyethanol, 4-amino benzoic acid, methylisothiazolidone. ${ }^{24-26}$ In particular, sodium lauryl sulfate that is one of the most commonly used excipients in cosmetic products, has been found to cause allergic contact dermatitis and has strong irritant properties by causing a high rate of transepidermal water loss. ${ }^{27}$ Paraphenylenediamine used in hair dyes and benzophenone-3, which is frequently used in sunscreens, are also high-contact dermatitis allergen. ${ }^{28-30}$ Cosmetics containing keratolytic and chemical peeling agents such as alpha and beta hydroxy acids, retinoids, trichloroacetic acid, and kojic acid may cause irritant contact dermatitis. ${ }^{31}$

\section{b. Discoloration of the skin}

Ochronosis, which is one of the cutaneous adverse reactions, may occur after the application of cosmetics containing hydroquinone, a skin whitening agent.32,33 Ochronosis is a disease characterized by pigmentation in soft tissues due to lack of homogentisic acid oxidase enzyme, first described by Virchow ${ }^{34}$ for the first time. Hydroquinone causes depigmentation as it causes necrotic destruction of melanocytes. The use of hydroquinone in cosmetics is prohibited in EU countries, as depigmentation is irreversible. ${ }^{33}$ Another undesirable effect is related to skin bleaching cosmetics containing mercury, which is also prohibited in cosmetics at this time. ${ }^{32}$

\section{c. Acne cosmetica}

Kligman and Mills ${ }^{35}$ defined the table as characterized by the acneiform eruption on the lower cheek and chin due to the use of cosmetic products in women aged 20-50 years as Acne cosmetica. To determine which cosmetic ingredients cause Acne cosmetica, many studies have performed a comedogenicity test using rabbit ear canals. The test technique consists of applying the cosmetic ingredient samples to the ears of adult female albino rabbits daily for 4 consecutive weeks according to the rabbit ear comedogenic assay. At the end of 4 weeks, each rabbit ear was biopsied and examined for evidence of comedone formation. Isopropyl myristate, isopropyl palmitate, butyl stearate, octyl palmitate, octyl stearate, petroleum jelly, lanolin, some red dyes (D\&C red dyes, xanthine, and monoazoaniline), and paraffin are among the components that are considered comedogenic. ${ }^{35-38}$

\section{d. Endocrine disruptor effect}

An endocrine-disrupting substance is defined as an exogenous substance that causes disturbances in endocrine activity in a healthy organism or its generations. ${ }^{39}$ Endocrine disruptors affect endocrine functions by directly or indirectly activating or inhibiting hormone receptors and hormone metabolism enzymes. ${ }^{40}$ Endocrine-disrupting components change cellular signals by binding to hormone receptors. ${ }^{41}$ Reproductive impairment, diabetes, obesity, and breast cancer are major health problems associated with exposure to endocrinedisrupting chemicals.

Estrogenic chemicals can stimulate or inhibit transcriptional or post-transcriptional mechanisms by binding to estrogen or androgen receptors, with their similarity to the chemical structure of estrogen. ${ }^{42}$

Although a direct relationship between cosmetic use and endocrine-disrupting components is not yet clear, molecules known to have endocrine-disrupting activity are also used in cosmetics by experimental studies. ${ }^{43}$ The most common endocrine-disrupting components in cosmetics are parabens, bisphenol $A$ and phthalates. ${ }^{24,41}$ In addition to these, aluminum salts and triclosan are also cosmetic ingredients responsible for breast cancer by showing the estrogenic activity. ${ }^{44}$ According to the World Health Organization (WHO), triclosan is in the endocrine disruptor class. ${ }^{45}$

With the detection of parabens in vivo and in vitro tests performed on breast tumor tissues, the suspicion of cosmetic preparations especially applied to the armpit has increased..$^{46}$ Methylparaben, ethylparaben, propylparaben, and $n$-butyl paraben show estrogenic activation in MCF7 breast cancer cells. ${ }^{47}$ Also, breast cancer cells are mostly observed in the upper-outer region of the breast and one of the risk factors of this situation is the use of antiperspirants containing aluminum. ${ }^{48,49}$

Because of many studies, paraben derivatives are estrogenmimetic preservatives and can cause changes in hormone levels by interacting with estrogenic receptors. ${ }^{50-52}$ Thus, the paraben derivatives have been identified as a risk factors in the development of breast cancer. ${ }^{51,52}$ Considering those cosmetic products containing paraben are mostly products that remain in the body without washing, it is risky to apply to most of the body for daily use. Especially during pregnancy, it is critical to make changes in cosmetic use habits, to get support from physicians and pharmacists, and to take measures to minimize the risk of exposure to endocrine-disrupting components. ${ }^{43}$ 


\section{e. Other common systemic side effects}

A cosmetic product should not permeate through the skin and enter the systemic circulation. Cosmetic products only show efficacy through the epidermis and dermis. However, changes in particle sizes and chemical properties for active ingredients to be more effective may cause them to be absorbed from the skin and participate in circulation. Here, to be able to report correctly in the cosmetovigilance system, it is necessary to measure what percentage of the applied cosmetics is in the systemic circulation or how much bioaccumulation will occur. Unfortunately, these phenomena are not easy to follow.

\section{Percutaneous absorption of cosmetics}

Systemic side effects of cosmetic substances can only occur because of percutaneous absorption. A topically applied preparation must first penetrate the lipophilic layer. However, high lipophilic content that passes the Stratum corneum cannot pass into the hydrophilic dermis.

Percutaneous absorption occurs in 3 stages. In the first stage, the substance adheres to the Stratum corneum. In the second stage, permeation occurs with the passage of the substance between the layers. In the last stage, the substance passes through the blood vessels, into the systemic circulation. ${ }^{53}$

Permeation from stratum corneum occurs via intracellular, intercellular, and follicular routes:

- Hydrophilic molecules undergo intracellular transmission. In the intracellular pathway, molecules do not pass through corneocytes, but through them.

- The intercellular pathway is a cross between lipids (ceramide, cholesterol, fatty acids) in the stratum corneum, lipophilic molecules are permeated in this way.

- The follicular pathway occurs through hair follicles or sweat glands.

Factors such as the water ratio and lipids of the stratum corneum, the size and diffusion coefficient of the molecule, the number of hydrogen bond donors and recipients are physicochemical factors affecting percutaneous absorption. ${ }^{53}$ To pass the stratum corneum, the molecule must be of lipophilic character and of a size less than 500 Da. ${ }^{54}$ However, lipophilic structures cannot reach the dermis even if they pass the stratum corneum. Therefore, lipophilic structures may cause accumulation in the stratum corneum.

Physical methods such as iontophoresis, phonophoresis or chemical penetration enhancers can be used to increase the permeation of molecules through the skin.

\section{Penetration enhancers}

Penetration enhancers increase penetration by changing the physicochemical structure of the stratum corneum and reducing its resistance to diffusion. The denaturation of proteins in the stratum corneum and dissolution in skin lipids is the mechanism of action of penetration enhancers. By causing conformational changes in the stratum corneum proteins, the penetration of polar structures increases the penetration of non-polar structures by liquefying the crystalline lipids. ${ }^{55}$ Some penetration enhancers show these effects by two mechanisms. However, if the benefit-harm ratio of these chemicals is properly scrutinized, otherwise they may irritate [e.g. dimethyl sulfoxide (DMSO)]. Examples of penetration enhancers are surfactants, urea, fatty acids (oleic acid, undecanoic acid), terpenes (menthol, thymol), sugars (cyclodextrin), sulfoxides (DMSO), azone. ${ }^{53,55}$

Side effects related to cosmetic ingredients entering the systemic circulation

The formulation ingredients may be responsible for mutagenic, carcinogenic or genotoxic activities. The best known of these components is hexachlorophene, $p$-phenylenediamine, and zirconium complex. It has been reported that the usage of zirconium complex, which is used in antiperspirant products, in the form of aerosol causes the formation of granulomas in the lung, and the use of this substance in aerosol is prohibited. ${ }^{56}$

Some of the cosmetic ingredients found to be carcinogenic can be listed as $p$-phenylenediamine, aluminum, cocamide diethanolamine, butylated hydroxytoluene, coumarins, petrolatum, nickel, and mercury. ${ }^{24}$

In a study conducted on 169 oxidative hair dyes, 150 of them were found to be mutagenic. 2,4-diaminozole, 4-nitro-o-phenylenediamine, 2-nitro- $p$-phenylenediamine, 2-5-diaminoazole, 2-amino-5-nitrophenal, o-phenylenediamine, 2-amino-4-nitrophenol found in hair dyes and 2,5-diaminotoluene showed various levels of mutagenicity according to the Ames test. Strong mutagenic effects of $p$-phenylenediamine, 2,5-diaminotoluene, and 2,5-diaminozole were found after oxidation with hydrogen peroxide..$^{57}$

In a study in which the absorption of oxidized amine derivative hair dyes from the skin was monitored, $3.66 \mathrm{mg}$ metabolite of 2,5-diaminotoluene was found in the urine 2 days after the hair was dyed. Accordingly, it has been reported that in each hair dyeing process, approximately $4 \mathrm{mg}$ content is absorbed from the scalp and many aromatic amines and diamines are absorbed from the skin. ${ }^{58}$ Hair dyes are exposed not only through the skin but also through inhalation. For this purpose, there are various studies on the exposure of hairdressers to hair dyes. ${ }^{59}$

Diazolidine urea and imidazolidine urea, which are added to cosmetic preparations as preservatives, release formaldehyde. Ryu et al..$^{60}$ investigated the effects of benzalkonium chloride, diazolidine urea, and imidazolidine urea on apoptosis. Increased reactive oxygen species (ROS) production and decreased cell vital activities were observed at high concentrations of these substances in mouse cells. ${ }^{60}$ With these results, it has been reported that benzalkonium chloride, diazolidine urea, and imidazolidine urea used as preservatives in cosmetics cause ROS induction and apoptosis. 25\% of the ingredients of cosmetic products sold in the USA contain ingredients that release formaldehyde. ${ }^{61}$

Cadmium, chromium, and nickel are group 2 carcinogens, according to the International Agency for Research on Cancer. ${ }^{62}$ Arsenic, cadmium, copper, nickel, manganese, lead, and cobalt are metals used in limited concentrations in lip paints. ${ }^{63}$ However, although the formulation components have certain usage limits, cumulative effects can occur with the prolonged 
use of these formulations. Unintentionally digested metals can reach vital organs through systemic circulation. ${ }^{64}$

Besides, it has been shown in different studies that exposure to triclosan in pregnant women can cause developmental disorders in the newborn. ${ }^{65-67}$ Although it has been shown in studies that triclosan taken into the body with toothpaste remains within safe limits, it can have toxic effects by accumulating in adipose tissues in long-term use, and triclosan in pregnant women can pass to the placenta thanks to its pharmacokinetic properties. For this reason, healthcare professionals should recommend products that do not contain triclosan in pregnant women.

\section{CONCLUSION}

Because of all these findings, it is necessary to develop more conscious consumption habits against the unwanted side effects caused by cosmetics and cosmeceutical products, and the consultancy service to be provided by health professionals in this field become more important for public health. Therefore; it is necessary to publish guides and training to educate healthcare professionals as part of the cosmetovigilance system. Because it is known that health professionals do not pay enough attention to the side effects associated with cosmetics. ${ }^{16}$ Side effects due to reported cosmetic products are thought to be much less than those encountered. So that, healthcare professionals need to provide feedback on the cases they encounter with the forms available on TITCK's website for the cosmetovigilance system to function properly and to prevent possible risks. For public health, these reports should be made correctly.

Factors such as socio-economic developments, differing cosmetic trends, and marketing strategies increase people's cosmetic use trends. The increasing use of cosmetics causes people to be exposed to more chemicals. As we mentioned before, some chemicals such as parabens, phatalats, and metals may enter the systemic circulation and can accumulate in the human body. Taking the increase of cosmetic consumption and the special circumstances of some patient groups (kids and cancer patients into account, these types of products' safety assessments should be different from those of other cosmetic products).

Since cosmeceuticals have different effects compared with cosmetics, their control mechanisms and regulations also should be different from cosmetics. The unnamed gap between the two groups (cosmetics and drugs) creates uncertainty in the cosmetic market, which allows manufacturers to launch their products as "cosmetics". Besides, post-vigilance reporting should be an obligation for cosmetic companies to make the control mechanism of the institution easier and more effective.

There is a need for new studies in the academic field in which new ingredients are evaluated in terms of toxicology and their penetration through the skin. Newer production technologies (nanotechnology, biotechnology) and different active ingredients are used to achieve stronger effects in cosmetics. Changing cosmetic usage habits and contents creates the need to determine new regulations following the current situation.
Overall; serious and non-serious undesirable effects can be prevented with the cosmetovigilance system. The reporting process is the key of the system, therefore as a part of the feedback system, the healthcare professionals should be trained and supported in terms of cosmetovigilance. Some updates in regulations are needed to track Turkish changing cosmetic market.

\section{Ethics}

Peer-review: Externally and internally peer-reviewed.

\section{Authorship Contributions}

Concept: İ.A., M.Ü., Design: İ.A., M.Ü., Data Collection or Processing: İ.A., M.Ü., Literature Search: İ.A., Writing: İ.A., M.Ü.

Conflict of Interest: No conflict of interest was declared by the authors.

Financial Disclosure: The authors declared that this study received no financial support.

\section{REFERENCES}

1. Vigan M. New allergens in cosmetics. Cosmetovigilance. Ann Dermatol Venereol. 1997;124:571-575.

2. Tissier MH, Lepagnol F. Cosmetovigilance: a French pharmacovigilance system for cosmetics developed by the French health products safety agency. A proposal for the future. Therapie. 2002;57:273-282.

3. 76/768 EEC Cosmetics Directive. Official Journal of the European Communities, 1976. Available from: https://www.legislation.gov.uk/ eudr/1976/768/adopted

4. European Cosmetics Association, COLIPA Undesirerable Event Reports. European Comission, 2005. Available from: https://cosmeticseurope.eu

5. Council of Europe, Resolution ResAP. Committee of Ministers, 2006. Available from: https://rm.coe.int/09000016805d72f3

6. Regulation (EC) no $1223 / 2009$ of the European Parliament and of the Council of 30 November 2009 on cosmetic products. Available from: https://health.ec.europa.eu/system/files/2016-11/cosmetic_1223_2009_ regulation_en_0.pdf

7. Salverda JG, Bragt PJ, de Wit-Bos L, Rustemeyer T, Coenraads PJ, Tupker RA, Kunkeler LC, Laheij-de Boer AM, Stenveld HJ, van Ginkel CJ, Kooi MW, Bourgeois FC, van Gorcum TF, van Engelen JG, van Dijk R, de Graaf J, Donker GA, de Heer C, Bruynzeel D. Results of a cosmetovigilance survey in the Netherlands. Contact Dermatitis. 2013;68:139-148.

8. Sautebin L. Understanding the adverse effects of cosmetics: a pilot project in cosmetovigilance. Drug Saf. 2008;31:433-436.

9. FDA. Available from: https://www.fda.gov/cosmetics/cosmetics-lawsregulations/it-cosmetic-drug-or-both-or-it-soap

10. FDA. Available from: https://www.fda.gov/drugs/over-counter-otc-drugmonograph-process

11. 1223/2009 Borderline products. Available from: https://ec.europa.eu/ docsroom/documents/42850

12. Available from: https://ec.europa.eu/docsroom/documents/13032/

13. European Comission, "Medical Product Legislation." Official Journal of the European Union, 2004.

14. Kozmetik ürünlerin istenmeyen etkilerinin/ciddi istenmeyen etkilerinin kuruma bildirimine ilişkin kılavuz sürüm 1.0. Türkiye Illaç ve Tıbbi Cihaz 
Kurumu, 2005. Available from: https://titck.gov.tr/storage/legislation/ KeaTUbu4.pdf

15. Köse Ö, Sabuncuoğlu S, Erkekoğlu P, Koçer-Gümüșel B. Cosmetovigilance: current status in Europe and Turkey, its practices and cosmetovigilance surveys. FABAD J Pharm Sci. 2018;43:79-90.

16. Berne B, Tammela M, Färm G, Inerot A, Lindberg M. Can the reporting of adverse skin reactions to cosmetics be improved? A prospective clinical study using a structured protocol. Contact Dermatitis. 2008;58:223-227.

17. Di Giovanni C, Arcoraci V, Gambardella L, Sautebin L. Cosmetovigilance survey: are cosmetics considered safe by consumers? Pharmacol Res. 2006;53:16-21.

18. Yang SL, Zheng Y, Zhang YQ, Ye CX, Yi JL, Liu YF, Lai W. Cosmetics userelated adverse events. Chin Med J (Engl). 2019;132:2135-2136.

19. Al Mulla F, Sridhar SB, Shariff A, Abu Al Hassan G. Incidence, nature and causality assessment of cutaneous adverse reactions to cosmetics: a pilot study. Int J Community Med Public Health. 2019;6:1978-1983.

20. Adams RM, Maibach HI. A five-year study of cosmetic reactions. J Am Acad Dermatol. 1985;13:1062-1069.

21. Bodamyalı P. Yüz kontakt dermatitlerinde kozmetik allerjenlerle Patch test sonuçlarının değerlendirilmesi (Thesis). Ankara: Ankara University Faculty of Medicine; 2011.

22. Johansen JD, Aalto-Korte K, Agner T, Andersen KE, Bircher A, Bruze M, Cannavó A, Giménez-Arnau A, Gonçalo M, Goossens A, John SM, Lidén C, Lindberg M, Mahler V, Matura M, Rustemeyer T, Serup J, Spiewak R, Thyssen JP, Vigan M, White IR, Wilkinson M, Uter W. European Society of Contact Dermatitis guideline for diagnostic patch testing recommendations on best practice. Contact Dermatitis. 2015;73:195221.

23. Groot AC, Nater JP, Lender R, Rijcken B. Adverse effects of cosmetics and toiletries: a retrospective study in the general population. Int $\mathrm{J}$ Cosmet Sci. 1987;9:255-259.

24. Khan AD, Alam MN. Cosmetics and their associated adverse effects: a review. J App Pharm Sci Res. 2019:1-6.

25. Orton DI, Wilkinson JD. Cosmetic allergy: incidence, diagnosis, and management. Am J Clin Dermatol. 2004;5:327-337.

26. Jansson T, Lodén M. Strategy to decrease the risk of adverse effects of fragrance ingredients in cosmetic products. Am J Contact Dermat. 2001;12:166-169.

27. Freeman S, Maibach $\mathrm{H}$. Study of irritant contact dermatitis produced by repeat patch test with sodium lauryl sulfate and assessed by visual methods, transepidermal water loss, and laser Doppler velocimetry. J Am Acad Dermatol. 1988;19:496-502.

28. DeLeo VA. $p$-Phenylenediamine. Dermatitis. 2006;17:53-55.

29. Available from: https://ec.europa.eu/health/archive/ph_risk/committees/ scmp/documents/out43_en.pdf

30. Warshaw EM, Wang MZ, Maibach HI, Belsito DV, Zug KA, Taylor JS, Mathias CG, Sasseville D, Zirwas MJ, Fowler JF Jr, DeKoven JG, Fransway AF, DeLeo VA, Marks JG Jr, Pratt MD, Storrs FJ. Patch test reactions associated with sunscreen products and the importance of testing to an expanded series: retrospective analysis of North American Contact Dermatitis Group data, 2001 to 2010. Dermatitis. 2013;24:176182.

31. Pons-Guiraud A. Les allergies aux cosmétiques [Allergies to cosmetics]. Rev Prat. 2006;56:284-288.
32. Olumide YM, Akinkugbe AO, Altraide D, Mohammed T, Ahamefule N, Ayanlowo S, Onyekonwu C, Essen N. Complications of chronic use of skin lightening cosmetics. Int J Dermatol. 2008;47:344-353.

33. Desmedt B, Courselle P, De Beer JO, Rogiers V, Grosber M, Deconinck E, De Paepe K. Overview of skin whitening agents with an insight into the illegal cosmetic market in Europe. J Eur Acad Dermatol Venereol. 2016;30:943-950.

34. Virchow VR. XV. Ein fall von allgemeiner Ochronose der Knorpel und knorpelälinliclien Tlieile. De Gruyter. 1866. doi: https://doi. org/10.1515/9783112390542-015.

35. Kligman AM, Mills OH. Acne cosmetica. Arch Dermatol. 1972;106:843850.

36. Fulton JE Jr, Pay SR, Fulton JE $3^{\text {rd }}$. Comedogenicity of current therapeutic products, cosmetics, and ingredients in the rabbit ear. J Am Acad Dermatol. 1984;10:96-105.

37. Singh S, Mann BK, Tiwary NK. Acne cosmetica revisited: a case-control study shows a dose-dependent inverse association between overall cosmetic use and post-adolescent acne. Dermatology. 2013;226:337341.

38. Nguyen SH, Dang TP, Maibach HI. Comedogenicity in rabbit: some cosmetic ingredients/vehicles. Cutan Ocul Toxicol. 2007;26:287-292.

39. A Bergman, Heindel JJ, Jobling S, Kidd KA, Zoeller RT. State of the Science of endocrine disrupting chemicals - 2012 an assessment of the state of the science of endocrine disruptors. Available form: https:// apps.who.int/iris/bitstream/handle/10665/78102/WHO_HSE_PHE_ IHE_2013.1_eng.pdf?sequence=1\&isAllowed=y

40. Giulivo M, Lopez de Alda M, Capri E, Barceló D. Human exposure to endocrine disrupting compounds: their role in reproductive systems, metabolic syndrome and breast cancer. A review. Environ Res. 2016;151:251-264.

41. Natarajan R, Aljaber D, Au D, Thai C, Sanchez A, Nunez A, Resto C, Chavez T, Jankowska MM, Benmarhnia T, Yang JA, Jones V, Tomsic J, McCune JS, Sistrunk C, Doan S, Serrano M, Cardiff RD, Dietze EC, Seewaldt VL. Environmental exposures during puberty: window of breast cancer risk and epigenetic damage. Int J Environ Res Public Health. 2020;17:493.

42. Wuttke W, Jarry $H$, Seidlova-Wuttke D. Definition, classification and mechanism of action of endocrine disrupting chemicals. Hormones (Athens). 2010;9:9-15.

43. Marie C, Cabut S, Vendittelli F, Sauvant-Rochat MP. Changes in cosmetics use during pregnancy and risk perception by women. Int J Environ Res Public Health. 2016;13:383.

44. Darbre PD. Environmental oestrogens, cosmetics and breast cancer. Best Pract Res Clin Endocrinol Metab. 2006;20:121-143.

45. Bergman $\AA$, Heindel JJ, Jobling S, Kidd KA, Zoeller RT. Endocrine Disrupting Chemicals 2012. WHO: UNEP, 2012.

46. Darbre PD. Underarm cosmetics and breast cancer. J Appl Toxicol. 2003;23:89-95.

47. Byford JR, Shaw LE, Drew MG, Pope GS, Sauer MJ, Darbre PD. Oestrogenic activity of parabens in MCF7 human breast cancer cells. J Steroid Biochem Mol Biol. 2002;80:49-60.

48. McGrath KG. An earlier age of breast cancer diagnosis related to more frequent use of antiperspirants/deodorants and underarm shaving. Eur $\mathrm{J}$ Cancer Prev. 2003;12:479-485.

49. Jennrich $P$, Schulte-Uebbing C, P. Does aluminium trigger breast cancer? Open Access J Sci Technol. 2016:1-6. 
50. Prusakiewicz JJ, Harville HM, Zhang Y, Ackermann C, Voorman RL. Parabens inhibit human skin estrogen sulfotransferase activity: possible link to paraben estrogenic effects. Toxicology. 2007;232:248-256.

51. Darbre PD, Harvey PW. Paraben esters: review of recent studies of endocrine toxicity, absorption, esterase and human exposure, and discussion of potential human health risks. J Appl Toxicol. 2008;28:561578.

52. Boberg J, Taxvig C, Christiansen S, Hass U. Possible endocrine disrupting effects of parabens and their metabolites. Reprod Toxicol. 2010;30:301-312.

53. Bolzinger MA, Briançon S, J. Pelletier J, Chevalier Y. Penetration of drugs through skin, a complex rate-controlling membrane. Curr Opin Colloid Interface Sci. 2012;17:156-165.

54. Massella D, Argenziano M, Ferri A, Guan J, Giraud S, Cavalli R, Barresi $A A$, Salaün F. Bio-functional textiles: combining pharmaceutical nanocarriers with fibrous materials for innovative dermatological therapies. Pharmaceutics. 2019;11:403.

55. Kanikkannan N, Kandimalla K, Lamba SS, Singh M. Structure-activity relationship of chemical penetration enhancers in transdermal drug delivery. Curr Med Chem. 2000;7:593-608.

56. Kaymak $Y$, Tirnaksız F. Side effects related to cosmetic products. Dermatose. 2007;1:39-48.

57. Ames BN, Kammen HO, Yamasaki E. Hair dyes are mutagenic: identification of a variety of mutagenic ingredients. Proc Natl Acad Sci U S A. 1975;72:2423-2427.

58. Kiese M, Rauscher $\mathrm{E}$. The absorption of $p$-toluenediamine through human skin in hair dyeing. Toxicol Appl Pharmacol. 1968;13:325-331.

59. Herrinton LJ, Weiss NS, Koepsell TD, Daling JR, Taylor JW, Lyon JL, Swanson GM, Greenberg RS. Exposure to hair-coloring products and the risk of multiple myeloma. Am J Public Health. 1994;84:1142-1144.
60. Ryu O, Park BK, Bang M, Cho KS, Lee SH, Gonzales ELT, Yang SM, Kim S, Eun PH, Lee JY, Kim KB, Shin CY, Kwon KJ. Effects of several cosmetic preservatives on ROS-dependent apoptosis of rat neural progenitor cells. Biomol Ther (Seoul). 2018;26:608-615.

61. de Groot AC, Veenstra M. Formaldehyde-releasers in cosmetics in the USA and in Europe. Contact Dermatitis. 2010;62:221-224.

62. IARC Working Group on the Evaluation of Carcinogenic Risks to Humans, World Health Organization, and International Agency for Research on Cancer, eds. Some aromatic amines, organic dyes, and related exposures. Lyon: IARC Press, 2010.

63. Al-Salehl, Al-Enazi S. Trace metals in lipsticks. Toxicol Environ Chem. 2011;93:1149-1165.

64. Gao P, Lei T, Jia L, Yury B, Zhang Z, Du Y, Feng Y, Xing B. 2018;238:554561.

65. Jackson-Browne MS, Papandonatos GD, Chen A, Calafat AM, Yolton K, Lanphear BP, Braun JM. Identifying vulnerable periods of neurotoxicity to triclosan exposure in children. Environ Health Perspect. 2018;126:057001.

66. Allmyr M, Harden F, Toms LM, Mueller JF, McLachlan MS, AdolfssonErici M, Sandborgh-Englund $G$. The influence of age and gender on triclosan concentrations in Australian human blood serum. Sci Total Environ. 2008;393:162-167.

67. Berger K, Gunier RB, Chevrier J, Calafat AM, Ye X, Eskenazi B, Harley $K G$. Associations of maternal exposure to triclosan, parabens, and other phenols with prenatal maternal and neonatal thyroid hormone levels. Environ Res. 2018;165:379-386. 